\section{$\underset{\substack{\text { hommes } \\ \text { \& migrations }}}{ }$}

\section{Hommes \& migrations}

Revue française de référence sur les dynamiques

migratoires

$1305 \mid 2014$

L'exil chilien en France

\title{
Araucaria de Chile
}

La revue culturelle de l'exil chilien

\section{Melina Cariz}

\section{Q OpenEdition}

1 Journals

\section{Édition électronique}

URL : http://journals.openedition.org/hommesmigrations/2755

DOI : 10.4000/hommesmigrations.2755

ISSN : 2262-3353

\section{Éditeur}

Musée national de l'histoire de l'immigration

\section{Édition imprimée}

Date de publication : 1 janvier 2014

Pagination : 152-155

ISBN : 978-2919-040261

ISSN : $1142-852 X$

\section{Référence électronique}

Melina Cariz, «Araucaria de Chile», Hommes \& migrations [En ligne], 1305 | 2014, mis en ligne le 10 juillet 2014, consulté le 22 septembre 2020. URL : http://journals.openedition.org/hommesmigrations/ 2755 ; DOI : https://doi.org/10.4000/hommesmigrations.2755 


\title{
COLLECTIONS
}

\section{ARAUCARIA DE CHILE LA REVUE CULTURELLE DE L'EXIL CHILIEN'}

\author{
MELINA CARIZ, professeur de littérature latino-américaine à l'université \\ de Marne-la-Vallée
}

\section{La culture chilienne de l'exil}

L'exode massif provoqué par le coup d'État de septembre 1973 a donné naissance à une manifestation extrêmement vaste et vigoureuse : la culture chilienne de l'exil. Le Chili n'a jamais atteint comme alors une telle résonance planétaire. Dans de nombreux pays, artistes et intellectuels cinéastes, musiciens, peintres, écrivains, compositeurs - ont développé une activité culturelle sans précédent. La production artistique de la diaspora témoigne également de l'écho qu'a eu la tragédie chilienne à l'étranger. Dans la période de son plus grand essor, la revue Araucaria a été diffusée dans 37 pays, dans lesquels demeurait un noyau de Chiliens que le coup militaire avait fait fuir.

\section{Les causes de l'exil}

Ce n'est pas par hasard que des centaines de personnes liées à la culture quittèrent le pays. La société chilienne fut victime de ce qu'on appela à l'époque l'“apagón cultural", c'est-à-dire une coupure, une panne de courant culturelle. Ce terme désigne la destruction et l'abandon de projets culturels par la junte militaire - fermetures d'uni- versités, censure dans tous les domaines - ce qui provoque une fuite massive des cerveaux. Les intellectuels et les artistes quittaient le pays parce qu'ils étaient opposants à la dictature, parce qu'ils avaient perdu leur emploi ou parce qu'ils ne pouvaient supporter l'atmosphère étriquée et suffocante imposée par la dictature, d'autant plus palpable après la révolution culturelle qui avait fleuri sous le gouvernement de l'Unité populaire (1970-1973) du président Salvador Allende. C'est dans ces conditions que naquit Araucaria en 1978.

\section{Une revue pluridisciplinaire de la diaspora}

La revue Araucaria de Chile fut une parcelle de l'immense espace occupé par la culture chilienne de l'exil. Revue pluridisciplinaire, elle fut publiée de façon trimestrielle sans interruption pendant douze ans, entre 1978 et 1989, soit un total de 48 numéros. Elle circulait dans près de 50 pays, et même clandestinement au Chili. La rédaction siégea à Paris jusqu'en 1984. Cette année-là, elle fut transférée à Madrid, où, depuis ses débuts, on l'imprimait et on organisait sa distribution. Comme le raconte Carlos Orellana, son éditeur, Araucaria fut fondée un week-end de mai, en plein printemps européen. Même si le siège de 
Rojas Mix, Armando Uribe Arce, Radomiro Tomic, Gonzalo Arroyo, Patricio Manns, Juvencio Valle... Araucaria finit par devenir un objet culturel de référence obligatoire entre les Chiliens de la diaspora et parmi les intellectuels de culture hispanique en général.

\section{Les objectifs de la revue}

La publication de la revue Araucaria visait à répondre au terrible "apagón cultural" qui s'était abattu sur la société chilienne. C'est cette situation de décadence culturelle qu'Araucaria se proposait de combattre, comme le déclare l'éditorial du premier numéro. II s'agissait de concevoir la culture comme une forme de résistance et de combat politique, sans perdre de vue la rigueur intellectuelle.

La revue est née également de la douloureuse prise de conscience par la diaspora que la dictature et, par conséquent, l'exil allaient durer. Araucaria témoigne aussi des différentes étapes de l'exil. Dans un premier temps, les exilés eurent besoin d'évoquer, de se remémorer les

la rédaction se trouvait à Paris et que le directeur résidait à ce moment-là à Moscou, l'acte fondateur eut lieu à Rome : une fragmentation géographique à l'image de l'extension de la diaspora.

On publia énormément de revues pendant ces années-là, mais Araucaria fut l'une des plus importantes par l'ampleur des thèmes traités, par la qualité et l'intérêt de ses articles, par le prestige de ses collaborateurs. La revue attira, en effet, des incontournables de la culture hispanique. On peut citer, entre autres : Gabriel García Márquez, Julio Cortázar, Rafael Alberti, Ernesto Cardenal, Mario Benedetti, Ernesto Sábato, Carlos Fuentes, Eduardo Galeano, Francisco Coloane, Antonio Skármeta, José Miguel Varas, Jaime Concha, Hernán Soto, Volodia Teitelboim, Isabel Allende, Ariel Dorfman, Virginia Vidal, Ligeia Balladares, Cecilia Salinas, Olga Poblete, Eugenia Echeverría, Miguel circonstances de la prise de pouvoir des militaires. C'est ainsi que se développa le genre du témoignage qui n'avait jamais connu au Chili pareil essor. Araucaria offre un ample aperçu de cette écriture testimoniale. Par la suite, l'exil fut perçu, en tant que nouvelle condition, comme un objet d'étude sur lequel il fallait se pencher. Des écrivains, des sociologues, des psychologues, des historiens abordèrent la question de l'exil sous des angles à chaque fois différents.

\section{La diversité des profils de la première équipe}

De la première réunion constitutive à Rome à laquelle assistèrent Volodia Teitelboim, Carlos Orellana, Omar Lara, Hernán Loyola, Sergio Muñoz 
Riveros, Agustín Olavarría, Héctor Pinochet, seuls le directeur et l'éditeur nommés à ce moment-là ont pu poursuivre le travail au sein de la revue. Pour des raisons d'éloignement géographique, les autres membres sont devenus des collaborateurs extérieurs. L'équipe de rédaction initiale, composée d'Eugenia Neves (professeur de littérature), Soledad Bianchi (critique littéraire), Luis Bocaz (professeur et essayiste), Carlos Martínez (architecte), Osvaldo Fernández (professeur de philosophie) et Luis Alberto Mansilla (journaliste), permit de donner à Araucaria, grâce à la diversité professionnelle de ses membres, la physionomie espérée : celle d'une revue à la fois politique, littéraire, philosophique, journalistique et, de façon générale, tournée vers l'ensemble des sciences sociales, mais dont l'axe fédérateur était le Chili et, par extension, toute l'Amérique latine.

\section{Une revue latino-américaine qui s'adresse aux Chiliens}

Un des partis pris de la revue fut de privilégier les collaborateurs chiliens. La revue se proposait de donner aux Chiliens l'opportunité qu'offrait l'exil de "penser" le Chili, de se concentrer sur les problèmes spécifiques à la société chilienne. La revue offre ainsi un large éventail de la production culturelle de cette époque, aussi bien à travers la publication d'œuvres de création (narration, poésie, théâtre) que de travaux d'analyse et de critique.

Araucaria est aussi une revue latino-américaine qui s'adresse aux Chiliens, dans le sens où il s'agissait de leur offrir la possibilité de compléter et d'approfondir leur connaissance de la réalité latino-américaine. Jusqu'alors, les Chiliens avaient une attitude méprisante à l'égard de leurs voisins latino-américains, mais le coup d'État militaire de 1973 et la brutalité de la répression démontrèrent que la réalité chilienne était tout à fait semblable à celle des autres pays latino-américains. Les Chiliens apprirent dans l'exil qu'ils ne pourraient jamais comprendre l'histoire de leur pays s'ils ne n'inscrivaient pas dans l'histoire plus vaste du continent. La revue s'est donc proposé d'œuvrer pour cet élargissement de perspectives. À l'image de l'arbre appelé araucaria, la revue voulut s'enraciner dans la culture de la terre mère, tout en recevant le vent des courants universels.

La revue finit donc par développer un style propre, différent de celui des autres publications similaires : une revue militante au contenu exigeant, où le slogan fut remplacé par la réflexion.

\section{La dimension politique de l'exil}

La dimension politique de la revue est perceptible dès sa création. Elle fut, en effet, fondée à l'initiative de la direction extérieure du Parti communiste chilien qui siégeait alors à Moscou et traversait une crise profonde. 1976 fut une année sombre pour la gauche chilienne : la politique répressive de la dictature s'était concentrée sur l'extermination des communistes et des militants d'extrême gauche, et les directions successives du PC furent exterminées.

Parallèlement, les années de la revue Araucaria à Paris sont liées à l'apogée de l'activité politique de l'exil chilien en France et de la solidarité française. Ce fut notamment le journal L'Humanité qui céda des locaux pour la rédaction. À Paris, la revue jouissait d'un nombre impressionnant de lecteurs : une multitude de réunions se déroulaient au Département d'études ibériques de la Sorbonne Nouvelle, à l'Institut des hautes études d'Amérique latine ou encore au théâtre JeanLouis-Barrault. Le premier colloque sur la littérature chilienne de l'exil fut organisé en juin 1983. 
Carlos Orellana y présenta une communication sur Araucaria.

En 1979, Pinochet montra la revue Araucaria à la télévision comme une preuve des moyens matériels dont jouissaient les marxistes pour arriver à leurs fins perverses et dangereuses. D'après lui, c'étaient des millions qui étaient requis pour publier une revue si "luxueuse". Réflexion amusante lorsqu'on sait que l'infrastructure humaine de la revue était presque inexistante. À part les trois premiers mois pendant lesquels la revue bénéficia d'une secrétaire, au long des douze années suivantes, Araucaria fonctionna grâce à deux personnes salariées : l'éditeur (Orellana) et un employé qui assurait le secrétariat et la distribution (Marcos Suzarte occupa ce poste au cours des dix dernières années). La revue manquait de moyens, il n'y avait pas de correcteur officiel et on travaillait sur une vieille machine à écrire.

\section{Les collaborateurs bénévoles}

L'aspect "luxueux" de la revue résidait surtout dans la qualité de la maquette. Ce fut Guillermo Tejada qui conçut le premier numéro ainsi que le logo de la revue, remplacé par la suite par Fernando Orellana. De plus, la revue bénéficia de la collaboration bénévole d'une centaine d'artistes plasticiens chiliens - peintres, sculpteurs, dessinateurs, graveurs, photographes -, tels que le peintre Roberto Matta. Araucaria présentait ainsi un éventail assez large de la production plastique de l'époque. Il est important de souligner qu'aucun collaborateur de la revue n'était payé. Aucune rémunération n'était prévue non plus pour les militants ni pour les amis de la cause chilienne, qui permirent sa distribution et sa vente. C'est pourquoi on peut dire qu'Araucaria reposait sur la solidarité. Le seul objectif des collaborateurs était de contribuer à la lutte contre la dictature.
Les dernières années, lorsqu'on soutenait que la dictature approchait de sa fin, la revue chercha des appuis au Chili et intégra des collaborateurs locaux en espérant s'installer au Chili dès que la situation politique le permettrait. Mais Araucaria cessa de paraître à la fin de l'ère Pinochet. La revue, intrinsèquement liée à l'exil, disparut à l'instar des conditions dans lesquelles elle avait été créée.

\section{Un patrimoine culturel}

La communauté d'intellectuels qui a été arrachée à son sol natal a trouvé dans l'écrit non seulement une forme de lutte politique, mais aussi une sorte de territoire.

Pour les exilés, l'écrit fut le lien avec le pays d'origine. Araucaria fut au cours de ses douze années d'existence la capitale de ce territoire fait de mots, d'analyses et de récits. Elle constitue par conséquent la mémoire de l'exil et l'héritage que les exilés laissent à leurs enfants restés en France ou retournés au pays.

Un patrimoine symbolique que le Musée de l'histoire de l'immigration a désormais la charge de sauvegarder, pour que tous ceux qui le souhaitent puissent savoir ce qui s'est pensé, écrit, rêvé au cours de l'exil chilien. Araucaria est aujourd'hui la source la plus précieuse pour qui souhaite approfondir la connaissance de ce qu'ont été la vie et l'activité créatrice du Chili extra-muros pendant la dictature. 